\title{
Miguel Angel Asturias en Italia
}

\section{ALgUNOS APUNTES BIO-BIBLIOGRÁFICOS}

La vida de un artista tiene siempre interés para la crítica, porque en muchas ocasiones ayuda a entender mejor su obra. Agradezco, pues, a los amigos Alfredo A. Roggiano y Pedro F. De Andrea la oportunidad que me ofrecen, en este número de la Revista Iberoamericana dedicado a Miguel Angel Asturias, para ilustrar un período de indudable importancia en su vida. Estas páginas, en las que van también indicaciones bibliográficas, son un homenaje al Maestro y al amigo, al cual desde ahora pido perdón por haberme atrevido a acudir a algunos pasajes de sus cartas con el fin de iluminar mejor ciertos momentos de su biografía.

El período a que me refiero es el que va de 1963 a 1966, años en que, a pesar de sus muchos viajes por Europa, Asturias residió preferentemente en Italia. Hubo hasta un momento en que pareció que el escritor pensaba radicarse en el país, en espera de tiempos mejores, cuando repentinamente las cosas cambiaron, fracasaron algunos proyectos y el improviso cambio político que se verificó en Guatemala le permitió ocupar nuevamente, con dignidad, un puesto importante en la carrera diplomática a la que habia renunciado, en acto de firme protesta, al realizarse la invasión de su país, en 1954.

Es éste un período difícil para los Asturias - doña Blanca es compañera fiel de la buena y la mala fortuna-, y a ello hacía alusión al terminar mi estudio sobre la narrativa del escritor guatemalteco. ${ }^{1}$ Comentando Mulata de tal ponía de relieve la presencia desgarradora de una Guatemala fabulosa en función de un ancla insustituible que valía tanto como impedir el naufragio de la esperanza. Añadía, sin embargo, que ni el mito ni la fantasía nunca eran fines en sí mismos, sino que penetraban en una región más intima del artista. En toda la narrativa última de

1 Cf. G. Bellini, La narrativa di Miguel Angel Asturias (Milano, Cisalpino, 1966), pp. 216.217. 
Asturias, lo mismo que en la poesía y el teatro, el combatiente de otro tiempo no ha cambiado, a pesar de que el escritor se nos presenta en un momento extraordinariamente "humano" de su existencia, cuando en las quemantes nostalgias de la patria se iban insinuando, mal reprimidas, notas de desaliento. Pero Asturias nunca ha renunciado conscientemente a su fe en el día de la justicia.

En 1964 Miguel Angel pensó que acaso sería posible reconstruir algo estable en su vida exrante. Los tiempos difíciles se iban acercando con el pasar de los años, sin que por ello renunciara, se entiende, a su ideal, en nombre de un gran amor americano. En 1963, a través del doctor Amós Segala, Asturias había entrado en contacto con "Columbianum", una entidad que en Génova se ocupaba de relaciones culturales entre Italia, América Latina y el Tercer Mundo. El prestigio del escritor guatemalteco era ideal para una tarea semejante y se pensó en la fundación de una gran revista dedicada a América, que Miguel Angel dirigiría. El escritor aceptó con entusiasmo y se dedicó a la empresa: se estudia la fórmula, se piensa en los colaboradores y en los editores. Asturias parece feliz, porque al fin puede hacer algo para su tierra. En carta desde Génova, el 20 de junio de 1964 escribe:

[...] en carta futura le contaré todo lo de la Revista, que ya es casi un hecho. No le quiero adelantar mucho, pero puedo afirmarle que será lo que pensamos: un puente entre Europa, más propiamente Italia, y América Latina. Todos los arreglos van muy adelantados $[\cdots]$

En carta sucesiva de 15 de julio las cosas parecen marchar viento en popa: se ha encontrado ya el editor y se piensa en una mesa redonda para la fundación de la revista:

[‥] Revista: Es un hrcho. Rizzoli la publicará. Está aceptado. Será como habíamos pensado: trimestral, 400 páginas, revista para biblioteca, sin ficción, puros estudios y ensayos [...] Del 6 al 10 habrá en Columbianum una mesa redonda, un coloquio para el que invitaremos a lo más granado de nuestros escritores, sociólogos, etc., etc. Esta reunión, además de su interés inmediato, tendrá el de ser el inicio de la revista, pues con lo que se discuta y hable en esa mesa redonda, se preparará el primer número, que aparecerá en febrero de 1965. Además, allí se echan las bases para que la revista perviva siempre en primer plano del interés de los lectores $[\ldots]$ 
A fin de realizar la mesa redonda Asturias viaja a París, para "comprometer a venir" a varias personalidades de la cultura internacional, y también para recoger sus cosas; es el momento en que los Asturias piensan instalarse definitivamente en Génova, para que Miguel Angel pudiera dedicarse completamente a la proyectada empresa cultural. La mesa redonda se realizó en diciembre de 1964 y, a pesar de las inevitables acciones de molestia y las envidias, ya no es una pequeña reunión, sino un verdadero "Congreso para la fundación de la Revista AMÉrica LATINA", con la participación de los nombres más significativos de la cultura latinoamericana y europea. El tema tratado es la formación y el desarrollo, la originalidad y las vinculaciones de la cultura y el arte latinoamericanos. Frente a tanto éxito Asturias cree firmemente que va a realizarse algo extraordinario, y lo expresa en el discurso inaugural:

No sé, pero en este grandioso espectáculo de la ciudad de Génova, cubierta de historia gloriosa, de hazañas y palacios, en esta ciudad rampante desde el mar hacia las colinas, nos sentimos ya un poco en América; tan grande es el ventanal de su luminosa bahía y tan poco el océano para nuestro anhelo de estar allá, lo que nos hace afirmar que este encuentro no ocurre en tierra extraña $[\ldots]^{\text {" }}$

En las palabras citadas asoma una nota evidente de nostalgia, natural en el exilado y que va cavando siempre más hondo, con el tiempo, en una zona intima del escritor. Es en este clima donde nacen las obras maestras del nuevo momento artístico de Miguel Angel Asturias, empezado ya con Mulata de tal. El poema Clarivigilia primaveral, aunque iniciado en París en el verano de 1963, pertenece, en realidad, sobre todo, al período italiano, como indica la edición bonaerense. ${ }^{3} \mathrm{La}$ inmersión en el mundo ancestral es para el poeta un reftrgio $y$ al mismo tiempo un alimento espiritual en el tormento del exilio. Se levantan asi esas "voces de piedra, madera, viento y nube" que realmente para el "lúcido y sensible" son "claras noticias" de su "clave ancestral"." Clarivigilia primaveral representa, por otra parte, el momento más alto de la poesía de Asturias, el único verdaderamente grande, frente al cual todos los versos

2 Terzo Mondo e Comunità Mondiale, testi delle relazioni presentate e lette ai Congressi di Genova, "Columbianum" (Milano, Marzorati, 1967), p. 166.

3 La edición de Clarivigilia primaveral (Buenos Aires, Losada, 1965), lleva al final del poema (p. 121) la indicación: "París, verano, 1963./Sinaia (Rumania), invierno, 1964./Venecia, Nápoles, Milán, Roma, Génova, 1964./Terminado en Génova, el 13 de julio de 1964."

4 Dedicatoria desde Roma, del 26 de febrero de 1966, de la edición francesa de Claritigilia primaveral (París, Gallimard, 1965). 
anteriores, por importante que sea su mensaje y su perfección artística, desaparecen. Sumergiéndose en las antiguas cosmogonías mayas, el poeta reivindica, a través de una arquitectura poética deslumbrante, la función humana de las artes.

La elaboración de Clarivigilia primaveral es larga y complicada. Asturias realizó primero una-redacción en prosa, en forma de novela; pero, insatisfecho del resultado y casi dominado por un delirio creativo -así me dijo-, acudió a la poesía. En marzo-abril el poema estaba terminado. Por esa época estaba en mis manos un ejemplar que debía servir para un proyecto de edición cuidada por el famoso impresor Tallone, "imponderable mago de las locomotoras o colamotoras", como lo llama Asturias." Meses antes habíamos hecho una visita a la casa-imprenta de Alberto Tallone, en Alpignano, cerca de Turín, y Miguel Angel habia quedado deslumbrado frente a la singularidad de la recepción: dos locomotoras de tren - Tallone era apasionado por estas máquinas- echando gran cantidad de humo desde sus chimeneas: era el ritual reservado a los huéspedes de excepción.

El proyecto de edición del poema no se realizó con la rapidez esperada, y mientras tanto Asturias, siempre insatisfecho, lo rehizo totalmente. Con motivo del envío del poema "Tiempo y muerte en Copán", que debía servir para la antología poética que estaba preparando, ${ }^{6}$ escribía desde Génova, el 20 de junio de 1964:

[...] En cuanto al poema "Clarivigilia Primaveral", mea culpa, mea grandísima culpa, tuve aquí en Génova a la mano un magnetófono, una inmensa soledad, ni un solo ruido, alojados como es. tamos lejos de la ciudad, entre colinas y el mar, en un séptimo piso, y casi rehice el poema. Su estructura, desde luego, ha quedado igual, pero muchos versos cambiaron, otros desaparecieron, $y$, en fin, que está bastante reformado. Pero "para mejor", como dicen en mi tierra. Creo que ahora sí está a la medida de lo que la imperfección humana puede lograr. Valéry decía que en un poema, lo imperfecto debe uno atacarlo en toda forma, reducirlo a ceniza si es preciso, cuando esto depende de uno, de su voluntad de trabajo, de su posibilidad de inspiración, pues, siempre quedará, decía Valéry, lo que de imperfecto hay en toda obra humana, pero im-

${ }^{5}$ Carta desde Roma, del 30 de marzo de 1964. El ejemplar mencionado presenta gran interés, como se verá en una próxima publicación mía.

6 Esta antología se publicó bajo el título de Parla il Gran Lengua (Parma, Guanda, 1965), y en segunda edición, aumentada, en enero de 1967. 
perfección que ya no depende de uno, ni de su empeño, ni de su afán, ni de su voluntad $[\ldots]$

El hecho es que la zona sentimental de Miguel Angel Asturias era más que nunca guatemalteca en Génova. La visión poética de este mundo, cual se realiza en Clarivigilia primaveral, se manifiesta con la misma intensidad en 'el "Pórtico", estupendo, a El espejo de Lida Sal y en la serie de evocaciones poéticas que forman este libro de "paisajes dormidos", donde la luz es "de encantamiento y esplendor". ${ }^{7}$ En gran parte de estas páginas sale a flote, único, en un mundo que ha borrado toda distinción entre realidad y sueño, un

País verde. País de árboles verdes. Valles, colinas, selvas, volcanes, lagos verdes, verdes, bajo el cielo azul, sin una mancha. $Y$ todas las combinaciones de los colores florales, frutales y pajareros en el enjambre de las anilinas. Memoria del temblor de la luz. ${ }^{8}$

Asturias escribe estas páginas durante su residencia italiana. Es una manera de vencer la lejanía. En el altillo del palacio Doria, adonde Asturias se traslada en el invierno de 1964 para estar más cerca de Columbianum, en el impiadoso frío genovés, al que con escaso éxito se oponían en los cuartos sin confort, dos estufas de kerosén, revivia una Guatemala intima, esperanzada y generosa, al atoma del café eternamente hirviendo, distribuido con liberalidad por doña Blanca - acaso también para ayudar a la calefacción-, atmósfera acogedora que presidía el "Gran Lengua".

A pesar de tan buen comienzo, el proyecto de la revista no progresó. Las editoriales italianas ven avanzar la crisis económica que se tragará a las menos previdentes. En Roma parece que hay editor, pero al fin toda esperanza se pierde. Desde París, adonde los Asturias se trasladaron al final de 1965 con la intención de quedarse por mucho tiempo, después de ir a Rostock para un seminario dedicado a Miguel Angel en la Universidad de dicha ciudad, escribe el novelista, el 7 de septiembre, aludiendo al asunto de la revista como a un sueño acabado:

[...] De la Revista de Columbianum no le hablo, pues no ha pasado a más, y mejor no meneallo, Sancho amigo [...]

7. M. A. Asturias, El espejo de Lida Sal (México, Siglo XXI, 1967), p. 3.

8 Ibid. 
No obstante, hasta la mitad de 1966 Asturias no deja de pasar largas temporadas en Italia. El fracaso de la revista le ha quitado muchas esperanzas, pero la vida prosigue, y es un continuo proyecto. En Italia el escritor tiene ya numerosos amigos, estudiantes que, durante sus varios cursillos sobre literatura latinoamericana, lo siguen entusiasmados. Las Universidades de Venecia, Turín, Padua, Nápoles, Roma, Milán le habían abierto sus aulas ya en otras ocasionales. ${ }^{9}$ Es frecuente en las cartas de Miguel Angel encontrar expresiones entusiastas por el interés encontrado entre profesores y estudiantes, $y$ sobre todo por el calor humano de algunos centros docentes. De ello se acordará en el momento de recibir el Premio Nóbel.

Francia e Italia son ahora los dos centros de interés de Asturias, mientras su nombre empieza a aparecer entre los candidatos al Premio de la Academia Sueca. En Italia se había publicado, en 1964, la traducción de Week-end en Guatemala, ${ }^{10}$ que seguía a larga distancia las de Ei Señor Presidente ${ }^{11}$ y El Papa verde.12 En 1965 se edita la traducción de Viento fuerte, ${ }^{13}$ se realiza una antología de la obra poética, ${ }^{14}$ y se editan los textos originales de los Sonetos de Italia, ${ }^{15}$ resultado, estos últimos, de un feliz encuentro con Venecia. El poeta ve a la ciudad lagunar en una soñadora y única geografía, cargada de historia y esplendor, de un pasado que induce a meditación y que la pone fuera de la realidad:

Aquí todo es ayer, el hoy no existe, huye en el agua, corre en los canales y va dejando atrás lo que subsiste, fuera del tiempo real, en las plurales

9 A mediados de julio de 1964 M. A. A. dicta también una serie de conferencias sobre novela latinoamericana en el tercer programa de la radio. El curso. se publicó luego con el título Originalità e caratteristicbe del romanzo latino-americano, Terzo programma, 4, 1964.

10 Week-end in Guatemala, trad. de Giuseppe Bellini (Milano, Nuova Accademia, 1964; $2^{\mathrm{a}}$ ed., en dos tomos, con los títulos de Tutti americani y Cadaveri per la pubblicità, respectivamente, 1965 ).

11 Apareció bajo el título de L'Uomo della Provvidenza, il Signor Presidente, trad. de Elena Mancuso (Milano, Feltrinelli, 1958). La retótica fascista llamaba al "Duce" "el Hombre de la Providencia" y dé ahí el título de la traducción italiana de una novela que trata de un dictador. Una segunda edición del libro. es del final de 1967, después del Nobel, esta vez con el único título de Il Signor Presidente.

12 Il Papa verde, trad. de Attilio Dabini (Roma. Editori Riuniti, 1959).

13 Vento forte, trad. de Cesco Vian (Milano, Rizzoli, 1965).

14 La ya citada Parla il Gran Lengua.

15 M. A. Asturias, Sonetos de Italia (Milano, Cisalpino, 1965). La edición es un homenaje al autor de parte de la Universidad Bocconi, Facultad de Lenguas y Literaturas Extranjeras, de Milán, en ocasión de una conferencia de Asturias. 
Venecias que nos da la perspectiva de una Venecia sola, aqui cautiva. ${ }^{16}$

La preocupación maya del tiempo asoma en todos los sonetos, frente a la irrealidad de Venecia, y de repente la ciudad se le presenta a Asturias como un puente entre Italia y su patria. En la suspensión irreal de los palacios, entre agua y cielo, cosas y animales típicos de Venecia acentúan el misterio, en el marco resplandeciente de la pintura de Carpaccio. $Y$ Venecia es la ciudad, creo, que más ha sabido despertar la inspiración del poeta, precisamente por esa íntima relación con su mundo ancestral, también cargado de historia, de esplendor, y fijo en el tiempo. La nota. dolorosa de la condición errante del hombre asoma también por entre los versos venecianos.

La perspectiva del Premio Nóbel despierta ahora concretamente el interés de los editores hacia las obras de Asturias. Sin embargo la edición de las traducciones italianas tardan, $y$ mientras en Francia ya en 1965 sale la edición de Mulata de tal, última de las novelas de Asturias vertidas al francés, ${ }^{17}$ en Italia se nota, además de un gran retraso, un notable desorden cronológico, con respecto a la sucesión de las obras del escritor guatemalteco en castellano.

La traducción francesa de Clarivigilia primaveral sale a la luz a distancia de sólo dos meses de su publicación en Buenos Aires; ${ }^{18}$ lo mismo ocurrirá más tarde con respecto a El espejo de Lida Sal, que se edita en abril de 1967.19 En carta desde París, del 24 de abril de 1965, manifiesta Asturias su satisfacción por el éxito que va teniendo la traducción de Mulata:

16 "Venecia, la cautiva", ibid., p. 16.

17 Aparece con el título de Une certaine Mûlatresse, trad. de Claude Couffon (Paris, Albin Michel, 1965), y concluye la larga serie de traducciones francesas, que cuenta con: Légendes du Guatemala, trad. de F. de Miomandre, prólogo de Paul Valéry (París, Gallimard, 1932; 2a ed. 1953; reimpresión 1962); Monsieur le Président, trad. de G. Pillement (Paris, Bellenand, 1952); L'Ouragan, trad. de G. Pillement (París, Gallimard, 1955); Le Pape vert, trad. de F. de Miomandre (París, Albin Michel, 1957); Week-end au Guatemala, trad. de G. Pillement (ibid., 1959); Les yeux des enterrées, trad. de M. Castelan (ibid., 1962).

18 Clarivigilia primaveral aparece en edición bilingüe, en la trad. de R. I. F. Durand (París, Gallimard, septiembre de 1965), mientras la edición de Buenos Aires es de julio del mismo año. Anteriormente había aparecido en Francia una antología poética de M. A. Asturias, Messages indieths, también con texto al frente, cuidada por C. Couffon (Paris, Seghers, 1958).

19 Le miroir de Lida Sal, trad. de C. Couffon (París, Albin Michel, 1967). En diciembre de 1964 el "Centre de Recherches de Y'Institut d'Etudes Hispaniques" de Paris habia editado ya un cuento de El espejo de Lida Sal, "Juan Girador". 
[...] ¡Muy felices Pascuas $y$ diez mil aleluyas! Le van con estas líneas dos de los comentarios que han salido $[\ldots]$ sobre Mutata de tal, libro que está causando gran sensación entre los críticos franceses, por tratarse de algo tan diferente, creo yo, a la mentalidad francesa, más que a la europea $[\ldots]$

Hacia la última década de octubre de 1965 los Asturias están en Roma, donde piensan quedarse por algún tiempo. La impresión causada por la capital italiana, antes negativa, es ahora favorable. Miguel Angel tiene proyectos de trabajo. Escribe desde la capital, el 22 de octubre:

[...] Nos quedamos, porque Roma está muy linda —así nos ha parecido esta vez-, para huir un poco del gris parisino, aquí hay cielo azul y sol, y porque quiero aislarme un poco para ver si termino la novela del Bastardo, que tengo empezada [...]

La elaboración de la novela mencionada es larga, sin embargo, y se prolongará en el tiempo, si es, como parece, la misma acabada de terminar en estos meses de 1968-69 y que lleva el nuevo título de El mal ladrón. ${ }^{20}$

Durante el período romano se intensifican los proyectos de traducciones, pero la edición italiana de El Albajadito verá la luz sólo al año siguiente, ${ }^{21}$ y la concesión del Premio Nóbel, en 1967, sorprenderá a los editores de las versiones de Mulata de tal y Hombres de maiz con los libros todavía en prensa. ${ }^{22}$ En cuanto a Los ojos de los enterrados, su traducción aparece sólo a fines de $1968,{ }^{23}$ y Clarivigilia primaveral, a comienzo de $1969 .{ }^{24}$

20 Parece que la edición castellana y las traducciones italiana y francesa saldrán simultáneamente. La versión italiana estará al cuidado de Amos Segala ₹ la publicará Rizzoli en 1969.

21 Aparece con el título La pozza del mendico, trad. de E. Mancuso (Roma, Veutro, 1966). El año anterior habia aparecido la traducción francesa de $D$. Eluard y A. Foppa, con el título La flaque du mendiant (París, Albin Michel, 1965).

22 Con la noticia del Premio Nobel aparecen apresuradamente: Malatta senzanome, trad. de C. Vian (Milano, Mondadori, 1967), y Uomini di mais, del mismo traductor (Rizzoli, 1967). Un detalle curioso: el editor de la traducción italiana de El señor Presidente, Feltrinelli, acababa de ceder a "Remainders Book" las copias que le habian quedado de dicho libro y se vio obligado a acudir con gran prisa a una nueva edición, para no perder los beneficios de venta que suponía la concesión del Ptemio Nobel al escritor.

23 Aparece con el título de Gli occhi che non si chiudono, trad. de C. Vian (Milano, Rizzoli, 1968) (noviembre).

${ }_{24}$ La traducción italiana de Clarivigilia primaveral la realiza Amos Segala y se edita en Milán, por Lerici, en el año de 1969. Especialmente interesante, en esta edición será el estudio introductotio al poema, para el cual Segala ha podido 
La residencia romana de los Asturias se prolonga más de lo pensado, hasta la primavera de 1966 y representa un momento singularmente feliz: en Roma viven muchos amigos, entre ellos los Alberti. Sin duda que el arte de la ciudad romana impresiona ahora profundamente a Asturias; un indicio, aunque leve, se puede sacar de una carta posterior, donde con cierto "humour" se firma: "Miguel Angel (el Buonarroti).":5 Coincidencia de nombres: Rafael Alberti, Miguel Angel Asturias, ambos en Roma.

Que la. residencia romana represente un período más sereno para los Asturias lo documenta también una carta que Miguel Angel escribe, en fecha 30 de abril de 1966, con objeto de una conferencia suya en Milán $\mathrm{y}$ en vísperas de regresar definitivamente a Paris. Trátase de una carta, interesante también, porque nos introduce en ese carácter tan abierto $\mathrm{y}$ alegre del escritor con sus amigos, y pienso que valga la pena reprodıcirla en parte:

Magnífico. El jueves 5 de mayo nos constituiremos en la ciudad de Milán, con doña Blanca. Yo hablo en la conferencia, y ella después [...] Pensábamos ir y seguir de Milán a París, pero era cargar con un millón de valijas, porque nuestro equipaje abarca: biblioteca ambulante, farmacia de urgencia (hasta pequeña cirugía), vestuario de verano e invierno, recortes de periódico que acreditan mi "genio" como los toreros, recetas de cocina, calentador eléctrico y de gas, cafetera napolitana, café especial, y perchas de colgar ropa, así como de esas otras pinzas de colores para tender prendas íntimas. Creo que esto faltó en su maravilloso libro. Pero eso vendrá cuando me pinten de pantuflas $[\ldots]$

La carta citada muestra un aspecto interesante del carácter de Miguel Angel Asturias; la nota de buen humor se impone frecuentemente, hasta en los momentos más difíciles de su vida. Con los amigos se abre y sobre ellos vuelca todo su afecto, les hace favores, y en ocasiones les dedica versos. $^{26}$

hablar diariamente, por largo tiempo, con el autor, en París. También interesante para la comprensión del poema son algunos pasajes del mismo Asturias en su Respuesta al bomenaje de la Universidad de Rostock, el largo ensayo de Adalbert Dessau, profesor en la misma Universidad, con motivo de la presencia del escritor, "Mythus und Wirklichkeit in Miguel Angel Asturias Bananentrilogie", Lateinamerika, Rostock, Frühjahrssemester, 1966. Otra aclaración del maestro aparecerå en un próximo número de Studi di letteratura ispano-americana, que edita la Universidad Bocconi, en Milán.

25 Carta desde Roma, del 22 de marzo de 1966.

26 Recuerdo, de paso, un interesante soneto, "Problema helado", que celebra 
Con la vuelta a París'se cierra el periodo italiano de Asturias. Los proyectos de viajes a Italia siguen, sin embargo, numerosos, y algunos se realizan, con intervenciones del escritor en las Universidades. Pero nuestro país ya no está en los planes del artista. Por otra parte, también la situación política de Guatemala parece cambiar. Hacia su pais Asturias tiene siempre fija la mirada, y en carta del 27 de junio de 1966 se entiende que al exilado se le abre la esperanza. Lamentando no haber agradecido antes la acogida en Milán, escribe con una nota de humor, a la que sigue una más trepidante:

[...] Creo que quizá hacemos esto los latinoamericanos de vez en vez, para que nuestros europeos amigos no se olviden que somos selváticos y bárbatos [...] Veremos cómo pintan las cosas de Guatemala, pues si se mejora iriamos, primero, a México, Guatemala y Argentina [...]

$Y$ efectivamente las cosas cambiaron. La larga agonía del destierro acaba. En carta desde Paris, del $1^{\circ}$ de agosto de 1966, Migucl Ange! escribe:

[...] Le saludo con un pie en el estribo del avión. Voy a Guatemala, después de 7 años de ausencia, a consultar con el Gobierno pues me nombrarnn Embajador en Francia [...]

Italia ya no es más, para los Asturias, a pesar de los momentos amargos, que un grato recuerdo. Sin embargo, cuando la Academia Sueca le concede el Premio Nóbel de Literatura, al final de 1967, Miguel Angel vuelve a este país: los editores lo han llamado para el lanzamiento de Hombres de maiz; pero su deseo es estar de nuevo con los estudiantes que le demostraron simpatía y afecto y se interesaron en su obra. A ellos, en una sesión imponente de homenaje al escritor, el hombre Asturias les agradece el calor humano con que siempre le acogieron y que le alentó, son palabras suyas, y le ayudó a superar no pocos desalientos y amarguras de sus años mảs recientes.

La concesión del Premio Nóbel despierta a la crítica italiana, por lo general no preparada para tal acontecimiento. Los periodistas acuden a la lectura apresurada de las obras de Asturias en las traducciones accesibles, y los juicios no son muy hondos; o se debate el eterno tema de

la habilidad de una amiga en preparar helados. El soneto está inédito, como otros escritos de M. A. Asturias. 
si el Premio Nóbel ha sido exactamente adjudicado, o poco menos. Más tarde aparecen estudios serios, no muy numerosos a la verdad, debidos ya a especialistas, y en los que el valor y la originalidad del escritor guatemalteco encuentran su justa evaluación. Entre ellos mencionaré los de Giuseppe De Gennaro, ${ }^{27}$ de Antonio Melis ${ }^{28}$ y Vittorio Bodini, ${ }^{29}$ sin olvidar a Cesco Vian, quien fue el primero en Italia, en el lejano 1956, en entender el valor de la obra de Miguel Angel Asturias. ${ }^{30}$

GiUSEPPE BELLINI

Universita Bocconi, Milano

27 G. de Gennaro, "I felici tropici di Miguel Angel Asturias narratore", La Civilià Cattolica, 119, 2822, 1968; "Il sentimento tragico della vita nell'opera di Asturias, Letture, XXIII, 5, 1968 (con una extensa nota bibliográfica). 28 A. Melis, "La parabola di M. A. Asturias", Ad libitum, 4, 1968.

29 V. Bodini, "Asturias e Sábato", en "Il volto dell'America Latina", Ulisse. $\mathrm{XXI}, \mathrm{IX}, 62,1968$.

so Cf. C. Vian, "Miguel Angel Asturias, romanziere-poeta del Maya d'oggi". Lingue e Cultura, II, 2, 1956. Al año siguiente apareció mi ensayo sobre La protesta nel romanzo ispano-americano del Novecento (Milano, Cisalpino, 1957). donde trato de $E l$ señor Presidente. 
